\title{
BMJ Global Health Prevalence and determinants of terminated and unintended pregnancies among married women: analysis of pooled cross-sectional surveys in Nigeria
}

\author{
Sanni Yaya, ${ }^{1}$ Agbessi Amouzou, ${ }^{2}$ Olalekan A Uthman, ${ }^{3}$ Michael Ekholuenetale, ${ }^{4}$ \\ Ghose Bishwajit, ${ }^{1}$ Ogochukwu Udenigwe, ${ }^{1}$ Alzahra Hudani, ${ }^{5}$ Vaibhav Shah ${ }^{5}$
}

To cite: Yaya S, Amouzou A, Uthman OA, et al. Prevalence and determinants of terminated and unintended pregnancies among married women: analysis of pooled cross-sectional surveys in Nigeria. BMJ Glob Health 2018:3:e000707. doi:10.1136/ bmjgh-2018-000707

Handling editor Seye Abimbola

Received 1 January 2018 Revised 9 April 2018 Accepted 13 April 2018

\section{Check for updates}

${ }^{1}$ School of International Development and Global Studies, University of Ottawa, Ottawa, Ontario, Canada ${ }^{2}$ Bloomberg School of Public Health, Johns Hopkins University, Baltimore, Maryland, USA

${ }^{3}$ Warwick Centre for Applied Health Research and Delivery (WCAHRD), Division of Health Sciences, Warwick Medical School, University of Warwick, Coventry, UK

${ }^{4}$ Department of Epidemiology and Medical Statistics, Faculty of Public Health, College of Medicine, University of Ibadan, Ibadan, Nigeria

${ }^{5}$ Interdisciplinary School of Health Sciences, University of Ottawa, Ottawa, Ontario, Canada

Correspondence to

Dr Sanni Yaya;

sanni.yaya@uottawa.ca

\section{ABSTRACT}

Background Induced pregnancy termination and unintended pregnancy are two commonly occurring phenomena in the discipline of women's reproductive health. In the present study, we explored crosssectional data pooled from three rounds of Nigeria Demographic and Health Survey (NDHS) to understand the trends of prevalence of pregnancy termination and unintended pregnancy as well as the interplay of various sociodemographic and economic factors whereby these health issues occur.

Methods Study participants were 79825 currently married women aged $15-49$ years. Data were collected from NDHS conducted in 2003, 2008 and 2013. Outcome variables were self-reported history of pregnancy termination and unintended pregnancy for the last birth. Data were analysed using descriptive and multivariable logistic regression methods.

Results Mean $( \pm S D)$ age of the respondents was 28.7 years $( \pm 9.6)$. The overall prevalence of pregnancy termination and unintended pregnancy were about $11 \%$. Older women had increase in the odds of terminated pregnancies, compared with women aged 15-19 years, while the converse was true for unintended pregnancy in the adjusted model. Educated women had significant higher odds of terminated and unintended pregnancies compared with women with no formal education. Women with higher wealth index were more likely to have unintended and terminated pregnancies after adjusting for other covariates. Remarkably, women who had unintended pregnancy were 1.47 times as likely to have terminated pregnancy compared with those who had no unintended pregnancy ( $O R=1.47 ; 95 \% \mathrm{Cl} 1.30$ to 1.65). Experience of intimate partner violence had significant association with terminated and unintended pregnancies. Conclusion The findings of this study showed that unintended and terminated pregnancies remain part of the issues to be addressed if the goal of ensuring healthy lives and promoting the well-being for all at all ages must be met. Stakeholders in Nigerian healthcare system should protect the lives of women who are vulnerable to the fatal consequences of unsafe abortion, especially in cases of rape, sexual assault, incest and where continuing a pregnancy would endanger the lives of women.

\section{Key questions}

What is already known?

- Prevalence of pregnancy termination and unintended pregnancy is considerably high in Nigeria.

What are the new findings?

- Important regional and sociodemographic disparities exist in the prevalence of pregnancy termination and unintended pregnancy.

- A great majority of the women were not using any modern contraceptive methods and had significantly higher likelihood of experiencing untended pregnancy.

What do the new findings imply?

- Family planning programmes in Nigeria should emphasise on promoting the utilisation of modern contraceptive methods. Most importantly, improvement in maternal healthcare services is needed to aid women during the challenges of unintended pregnancy.

\section{INTRODUCTION}

Unintended pregnancy is defined as unwanted (not wanted at that point of time) or mistimed (wanted but at a later time). Globally, unintended pregnancy has critical public, clinical and social health concern because it commonly results in induced abortion and eventually the complications which are usually due to poor abortion care services, especially in resource-constrained settings. ${ }^{2}$ It has been reported that of the estimated 210 million pregnancies that occur each year worldwide, approximately $38 \%$ are unplanned and $22 \%$ are terminated. ${ }^{3}$ Generally, more than 200 million women in developing countries would like to delay their next pregnancy or stop child birth altogether, 
nonetheless many of them still rely on traditional or less effective methods of contraception if at all they use any. ${ }^{4}$

Unintended pregnancy has often led to induced abortion, ${ }^{5}$ a known cause of maternal mortality in Nigeria particularly due to poor abortion care services. ${ }^{2}$ The negative outcomes of unintended pregnancies include late or no prenatal care seeking behaviour, induced abortions or engaging in social vices such as exposing the unborn to substance abuse and on the long run the childhood mortality which sometimes is due to insufficient resources for healthy development. ${ }^{6-8}$ More so, it reflects challenges in contraceptive access and use, increased risk of physical abuse and domestic violence, because majority of the unintended pregnancies occur among adolescents and youth, who become susceptible to gender-based violence due to lack of empowerment. ${ }^{9-11}$

In 2012, an estimated 59 unintended pregnancy and 33 induced abortions per 1000 women, respectively, were reported in Nigeria. This presupposes therefore that about $56 \%$ of unintended pregnancies resulted to abortion, while above 200000 women had complications due to unsafe abortion procedures. ${ }^{5}$ The outcome of abortion procedures is connected to the challenges in abortion policy and healthcare system. The Nigerian healthcare system operates within the Federal Ministry of Health which is responsible for strengthening the managerial and technical competence for delivery health services and setting standards, norms and protocols for vaccines, drugs, research, hospital services and human resource training for the sector development. ${ }^{12}$ Nigeria's abortion laws are currently restrictive, permitting it only to save the life of the pregnant woman. The concerns for the adverse impact of unintended pregnancy have necessitated attempts over time to secure reforms on abortion law in the country. ${ }^{13}$

In spite of the fact that induced abortion is illegal in Nigeria, unless when performed to save a woman's life, the act of induced abortion is prevalent and because they are usually performed secretly and mainly by unskilled care providers (traditional practitioners, herbalists, modern pharmacists to private clinicians), about half of the processes become unsafe. ${ }^{14}$ As a result of restrictive abortion laws, most abortions cannot be carried out in standard health facilities, making the process unsafe. ${ }^{1415}$ The consequences of these hidden abortions are enormous and can be life-threatening, often leading to maternal death. ${ }^{16}{ }^{17}$ Married women also experience unintended pregnancy, as they constituted about $35 \%$ and $63 \%$ of abortion seekers in two separate studies from South-western Nigeria. ${ }^{13} 18$

Several determinants predict the occurrence of unintended pregnancies and induced abortion including sociodemographic and economic factors, early sexual debut, accessibility to healthcare services, unmet need for family planning, higher parity, history of unintended pregnancy, contraception failure, partner's desire for children and domestic violence. ${ }^{6}{ }^{119}$ Notably, intimate partner violence (IPV) among women had 100\% increase to have an induced abortion than women who do not experience partners' abuse. ${ }^{20} 21$ The higher occurrence of induced abortion among the cohort of women with abusive male partners is due to the fact that abusive male partners are more likely to coerce a pregnant partner for induced abortion or continuing a pregnancy that would have preferably be terminated. ${ }^{21}{ }^{22}$ This study explores the prevalence and determinants of unintended and terminated pregnancies and would add to knowledge of the basis for the development of programmes and policies especially in a society that currently has no policy or legal approval to carry out abortion services. The objectives of this paper are to examine the prevalence of unintended and terminated pregnancies and identify key determinants of unintended pregnancy and induced abortion among Nigerian women.

\section{METHODS}

\section{Data source}

Data for this study were derived from $2003(\mathrm{n}=7607)$, $2008(\mathrm{n}=33318)$ and $2013(\mathrm{n}=38920)$ rounds of DHS in Nigeria that provided information on unintended and terminated pregnancies. The 10-year period was chosen to make plausible comparisons of the trend in the outcome variables (terminated and unintended pregnancies) of the study. In Nigeria, the surveys are implemented by the National Population Commission with the financial and technical assistance by ICF International provisioned through the USAIDfunded MEASURE DHS programme. DHS are nationally representative surveys that collect information on a wide range of topics such as demographic, socioeconomic, family planning and domestic violence to name a few. The survey covered men and women aged between 15 and 49 years and under- 5 children residing in non-institutional settings. DHS employed multistage stratified cluster design based on a list of enumeration areas (EAs). EAs are systematically selected units from localities, which constitute the Local Government Areas (LGAs). The LGAs are subdivisions of each of the administrative States (including the Federal Capital Territory (FCT)) and classified under six geographical zones. DHS used current census data conducted in 1991 with 21 federating States and a population of 87.5 million people during the 2003 survey. The sample was selected in two stages. In the first stage, 365 clusters were selected from a list of EAs developed from the 1991 population census. In the second stage, a complete listing of households was carried out in each selected cluster; households were then systematically selected for participation in the survey. ${ }^{23}$ However, the 2013 survey used the EAs from the 2006 population census data, with 36 federating States and the FCT, and a population of 140.4 million people. The 2013 Nigeria Demographic and Health Survey (NDHS) sample was selected using a stratified three-stage cluster design consisting of 904 clusters, 372 in urban areas and 532 


\begin{tabular}{|c|c|}
\hline Variables & Definition and coding \\
\hline Year & 2003/2008/2013 \\
\hline Age group of respondents & $\begin{array}{l}1=15-19 ; 2=20-24 ; 3=25-29 \\
4=30-34 ; 5=35-39 ; 6=40-44 ; \\
7=45-49\end{array}$ \\
\hline Type of place of residence & 1=Urban; 2=Rural \\
\hline Geographical region & $\begin{array}{l}\text { 1=North Central; } 2=\text { North East; } \\
\text { 3=North West; 4=South East; } \\
\text { 5=South South; 6=South West }\end{array}$ \\
\hline Education & $\begin{array}{l}0=\text { None; } 1=\text { Primary; } \\
2=\text { Secondary; } 3=\text { Tertiary }\end{array}$ \\
\hline Religion & $\begin{array}{l}\text { 1=Christianity; } 2=\text { =Islam; } \\
\text { 3=Other religion/none }\end{array}$ \\
\hline Employment & $0=$ Unemployed; 1 =Employed \\
\hline Sex of household head & $1=$ Male; $2=$ Female \\
\hline Household wealth status* & $\begin{array}{l}\text { 1=Poorest; 2=Poorer; 3=Middle; } \\
\text { 4=Richer; 5=Richest }\end{array}$ \\
\hline Total children ever born & $1=1-2 ; 2=3-4 ; 3=>4$ \\
\hline Modern contraceptive use & $0=\mathrm{No} ; 1=\mathrm{Yes}$ \\
\hline Domestic violence & $0=$ No; $1=$ Yes \\
\hline Intimate partner violence & $0=\mathrm{No} ; 1=$ Yes \\
\hline Marital status & $\begin{array}{l}1=\text { currently married/living with a } \\
\text { partner; } 2=\text { Not currently married }\end{array}$ \\
\hline
\end{tabular}

*For the calculation household wealth status, instead of direct income, the volume of durable goods (eg, TV, radio, bicycle) possessed by the household as well as and housing quality (eg, type of floor, wall and roof) are taken into consideration. Each item is assigned a factor score generated through principal component analysis which are then summed and standardised for the households. These standardised scores places the households in a continuous scale based on relative wealth scores. The scores thus obtained from a continuous scale and subsequently categorised into quintiles to rank the household as poorest/poorer/middle/richer/richest to richest. ${ }^{22}$ For the present study, households in lowest two categories were merged and categorised as poor, and those from middle to richest were merged as non-poor.

in rural areas. ${ }^{24}$ The increases in Nigeria population, number of federating States and stages of sampling were responsible for notable increase in the data size between 2003 and 2013.

\section{Outcome variables}

The outcome variables were (1) self-reported pregnancy termination and (2) intention status of last pregnancy. Both of the variables were categorised dichotomously as: (1) self-reported pregnancy termination (Yes/No) and (2) intention status (Intended/Unintended).

\section{Explanatory variables}

Based on a broad literature review and availability on the datasets, the variables given in table 1 were included in the analysis.

\section{Data analysis}

Data analysis was carried out using STATA 14 (Stata, College Station, Texas, USA). Datasets from three surveys $(2003,2008,2013)$ were merged into one to perform pooled analysis. To adjust for the cluster sampling techniques of the surveys, we used complex survey module (svyset) to account for primary sampling units, sample strata and sample weight. Following that, trend analysis for proportions was calculated using the Royston's p-trend approach ${ }^{25}$ to estimate $\chi^{2}\left(\chi^{2}\right.$ for trend statistic). In addition, $\chi^{2}$ tests were performed to examine the bivariate association between the outcome and explanatory variables. Variables that were found to be significant at alpha 5\% were entered into regression analysis. More so, only the more significant/basic variable was entered into the regression model for two variables that have collinearity. Two separate binary logistic regression analyses were carried out to calculate the ORs of the association between terminated and unintended pregnancy with the sociodemographic variables. The level of significance was set at alpha $5 \%$ for the regression models.

\section{Ethical consideration}

We did the analyses using publicly available data from demographic health surveys. All DHS surveys are approved by ICF international as well as an Institutional Review Board (IRB) in the host country to make sure that the protocols are in compliance with the U.S. Department of Health and Human Services regulations for the protection of human subjects. All participants gave informed consent before taking part in the survey. In this study, further ethical approval was not necessary as the analysis was based on secondary data available in the public domain in anonymised form. ${ }^{24}$

\section{RESULTS}

\section{Sample characteristics}

Results from table 2 showed that mean $( \pm \mathrm{SD})$ age of women was $28.7( \pm 9.6)$. Older women (40-49years) had lower percentage of unintended pregnancy, but for women aged 15-19 years, the report of terminated pregnancy was almost equal among other women. For geographical locations, women from South East had the least percentage of unintended and terminated pregnancies with $7.2 \%$ and $11.0 \%$, respectively. Meanwhile, women from North West geographical region had the highest percentages of unintended and terminated pregnancies ( $34.6 \%$ and $25.6 \%$, respectively). In addition, while rural residents had higher percentages of terminated and unintended pregnancies $(63.6 \%$ and $71.8 \%$, respectively). More so, women with no formal education reported more experiences of about $54.5 \%$ and $44.5 \%$ of unintended and terminated pregnancies, respectively. The results also showed that women reporting Islam as their religion had $46 \%$ and $58.3 \%$ of terminated and unintended pregnancies. 
Table 2 Characteristics of weighted sample population (NDHS 2003-2013)

\begin{tabular}{|c|c|c|c|c|c|c|}
\hline Variable & $\mathrm{n}=79825$ & Population \% & $\begin{array}{l}\% \text { of ever } \\
\text { terminated } \\
\text { pregnancy }\end{array}$ & $95 \% \mathrm{CI}$ & $\begin{array}{l}\% \text { of } \\
\text { unintended } \\
\text { pregnancy }\end{array}$ & $95 \% \mathrm{Cl}$ \\
\hline \multicolumn{7}{|l|}{ Age $(28.7 \pm 9.6)$} \\
\hline $15-19$ & 16204 & 20.3 & 3.8 & 3.30 to 4.20 & 6.6 & 6.20 to 6.90 \\
\hline 20-24 & 14261 & 17.9 & 11.7 & 11.00 to 12.50 & 19.3 & 18.80 to 19.80 \\
\hline $35-39$ & 9370 & 11.7 & 18.0 & 17.10 to 19.00 & 15.0 & 14.60 to 15.50 \\
\hline $40-44$ & 7387 & 9.3 & 15.0 & 14.20 to 15.90 & 8.2 & 7.90 to 8.60 \\
\hline $45-49$ & 7064 & 8.8 & 13.5 & 12.70 to 14.40 & 3.8 & 3.60 to 4.00 \\
\hline \multicolumn{7}{|l|}{ Region } \\
\hline South East & 9200 & 11.5 & 11.0 & 10.10 to 12.00 & 7.2 & 6.60 to 7.80 \\
\hline South South & 11793 & 14.8 & 14.1 & 12.90 to 15.40 & 8.8 & 8.20 to 9.50 \\
\hline South West & 12031 & 15.1 & 11.3 & 10.40 to 12.30 & 11.0 & 10.30 to 11.80 \\
\hline \multicolumn{7}{|l|}{ Residency type } \\
\hline Urban & 29046 & 36.4 & 35.2 & 33.20 to 37.20 & 28.2 & 26.60 to 29.90 \\
\hline Rural & 50779 & 63.6 & 64.8 & 62.80 to 66.80 & 71.8 & 70.10 to 73.40 \\
\hline \multicolumn{7}{|l|}{ Educational level } \\
\hline No education & 29925 & 37.5 & 44.5 & 42.70 to 46.30 & 54.5 & 53.00 to 56.00 \\
\hline Other & 5024 & 6.3 & 10.6 & 9.20 to 12.10 & 8.9 & 8.00 to 9.80 \\
\hline \multicolumn{7}{|l|}{ Employed } \\
\hline No & 30154 & 37.8 & 24.4 & 23.10 to 25.70 & 32.0 & 30.90 to 33.20 \\
\hline Yes & 49671 & 62.2 & 75.6 & 74.30 to 76.90 & 68.0 & 66.80 to 69.10 \\
\hline \multicolumn{7}{|c|}{ Sex of Household Head } \\
\hline Male & 65843 & 82.5 & 86.2 & 85.20 to 87.10 & 90.8 & 90.30 to 91.30 \\
\hline Female & 13982 & 17.5 & 13.8 & 12.90 to 14.80 & 9.2 & 8.70 to 9.70 \\
\hline \multicolumn{7}{|l|}{ Wealth status } \\
\hline Poorest & 15331 & 19.2 & 21.4 & 19.80 to 23.10 & 26.4 & 24.80 to 28.00 \\
\hline Poorer & 15698 & 19.7 & 20.6 & 19.30 to 22.10 & 24.8 & 23.70 to 25.90 \\
\hline Middle & 16075 & 20.1 & 19.6 & 18.40 to 20.90 & 19.6 & 18.60 to 20.60 \\
\hline Richer & 16518 & 20.7 & 19.2 & 18.00 to 20.50 & 16.4 & 15.50 to 17.40 \\
\hline Richest & 16203 & 20.3 & 19.1 & 17.70 to 20.50 & 12.8 & 12.00 to 13.60 \\
\hline \multicolumn{7}{|l|}{ Total child born } \\
\hline $1-2$ & 17149 & 21.5 & 21.7 & 20.70 to 22.80 & 33.2 & 32.60 to 33.90 \\
\hline $3-4$ & 15246 & 19.1 & 23.3 & 22.30 to 24.40 & 27.8 & 27.30 to 28.40 \\
\hline$>4$ & 47430 & 59.4 & 54.9 & 53.70 to 56.20 & 38.9 & 38.30 to 39.60 \\
\hline
\end{tabular}


Table 2 Continued

\begin{tabular}{|c|c|c|c|c|c|c|}
\hline Variable & $\mathrm{n}=79825$ & Population \% & $\begin{array}{l}\% \text { of ever } \\
\text { terminated } \\
\text { pregnancy }\end{array}$ & $95 \% \mathrm{Cl}$ & $\begin{array}{l}\text { \% of } \\
\text { unintended } \\
\text { pregnancy }\end{array}$ & $95 \% \mathrm{Cl}$ \\
\hline \multicolumn{7}{|c|}{ Currently use modern contraceptive methods } \\
\hline No & 71576 & 89.7 & 95.1 & 94.70 to 95.50 & 97.0 & 96.80 to 97.10 \\
\hline Yes & 8249 & 10.3 & 4.9 & 4.50 to 5.30 & 3.0 & 2.90 to 3.20 \\
\hline \multicolumn{7}{|l|}{ Unmet need } \\
\hline No & 56477 & 70.8 & 72.5 & 71.40 to 73.60 & 74.3 & 73.70 to 75.00 \\
\hline Yes & 23348 & 29.2 & 27.5 & 26.40 to 28.60 & 25.7 & 25.00 to 26.30 \\
\hline \multicolumn{7}{|c|}{ Experience of domestic violence } \\
\hline No & 62183 & 77.9 & 85.2 & 84.10 to 86.10 & 91.9 & 91.50 to 92.40 \\
\hline Yes & 17642 & 22.2 & 14.8 & 13.90 to 15.90 & 8.1 & 7.60 to 8.50 \\
\hline \multicolumn{7}{|l|}{ Marital status } \\
\hline $\begin{array}{l}\text { Currently married/living } \\
\text { with partner }\end{array}$ & 56385 & 70.5 & 88.3 & 86.1 to 90.0 & 78.8 & 76.7 to 81.3 \\
\hline Not currently married & 23568 & 29.5 & 11.7 & 8.9 to 13.4 & 21.2 & 18.8 to 23.5 \\
\hline
\end{tabular}

NDHS, Nigeria Demographic and Health Survey.

The results showed that about two-third of women who were employed had unintended pregnancies and approximately three-quarter of them had experienced terminated pregnancy. Women from households with male heads reported higher occurrence of unintended and terminated pregnancies $(90.8 \%$ and $86.2 \%$, respectively). There was steady increase from high to low wealth index for unintended and terminated pregnancies among women. Also, multiparous women had higher percentages ( $38.9 \%$ and $54.9 \%$, respectively) of unintended and terminated pregnancies. Women who do currently use modern contraceptive methods had approximately $97 \%$ and $95.1 \%$, respectively, occurrence of unintended and terminated pregnancies. Similarly, the results showed that women who had unmet need in contraceptive use had less of unintended and terminated pregnancies. Furthermore, about $8.1 \%$ of women who reported history of domestic violence had unintended pregnancies, while $14.8 \%$ of them had also experienced terminated pregnancy. Women who are currently married or living with partners had $78.8 \%$ and $88.3 \%$ of unintended and terminated pregnancies in Nigeria. See table 2 for details.

Figure 1 shows the trends of unintended and terminated pregnancies among women in Nigeria between 2003 and 2013. These were higher in 2003 (16.3\% and $14.5 \%$, respectively). However, there was a decline in these percentages over time; about $10.9 \%$ in 2008 and about $10.6 \%$ in 2013 . The trend analysis showed significant difference across the study period for terminated and unintended pregnancies (Terminated pregnancy: $\chi^{2}=62.565, \mathrm{p}<0.001 ;$ Unintended pregnancy: $\chi^{2}=57.762$, $\mathrm{p}<0.001)$.
Factors of terminated and unwanted pregnancies in Nigeria: 2003-2013

Based on the results from pooled data, the odds of terminated and unintended pregnancies in 2013 were $6 \%(\mathrm{OR}=0.94 ; 95 \%$ CI 0.87 to 1.01$)$ and $9 \%(\mathrm{OR}=0.91$; $95 \%$ CI 0.83 to 0.99 ) lower, compared with year 2003 after adjusting for other covariates. While older women had increase in the odds of terminated pregnancies, compared with women aged 15-19 years, the converse was obtained for unintended pregnancy in the adjusted model. Geographical region of respondents was significantly associated with terminated and unintended pregnancies. Further, rural dwellers had $4 \%$ reduction in the odds of unintended pregnancy, compared with their urban counterpart after adjusting for other covariates $(\mathrm{OR}=0.96 ; 95 \%$ CI 0.86 to 1.07$)$. However, there was $5 \%$ increase in the odds of terminated pregnancy among the rural dwellers (see table 3 for details). Educated women had significant higher odds of terminated and unintended pregnancies compared with women with no formal education.

Women who belonged to Islam and traditional religion had reduction in the odds of terminated and unintended pregnancies after controlling for confounders. In addition, the employed women were 1.11 times as likely to have terminated pregnancy compared with the unemployed $(\mathrm{OR}=1.11 ; 95 \% \mathrm{CI}=1.02$ to 1.21$)$, while $11 \%$ significant reduction of unintended pregnancy was obtained for employed women in the adjusted model ( $\mathrm{OR}=0.89 ; 95 \%$ CI 0.81 to 0.99$)$. Sex of household head was not significantly associated with terminated and unintended pregnancies. Women with higher economic status were more likely to have unintended and terminated pregnancies after adjusting for 


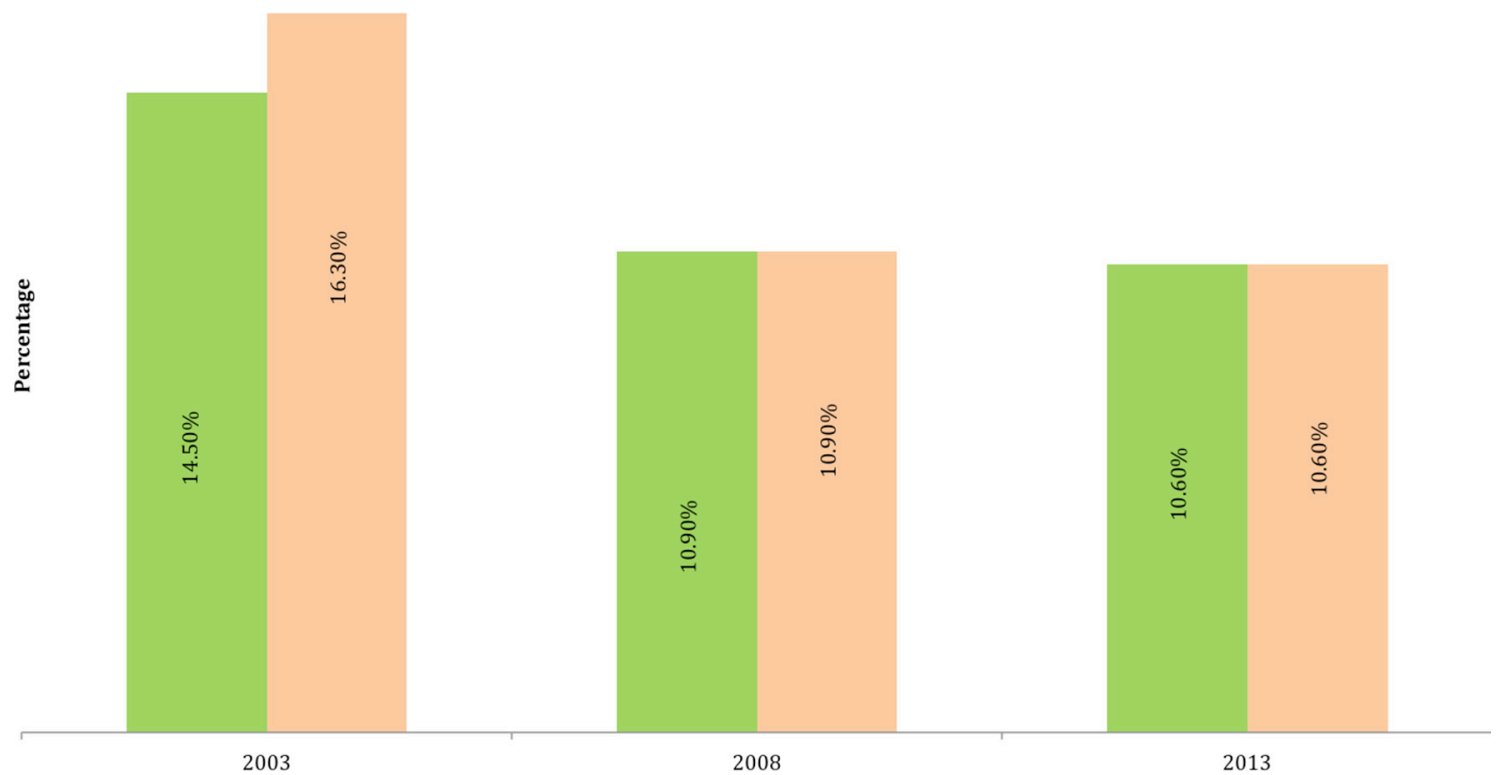

Figure 1 Trend of terminated and unintended pregnancy among women in Nigeria: 2003-2013.

other covariates. Above four children ever born among women were 2.57 times as likely to have unintended pregnancy compared with women with not more than two children ( $\mathrm{OR}=2.57 ; 95 \% \mathrm{CI}=3.75$ to 4.87$)$; however, women with more than four children had $10 \%$ reduction in terminated pregnancy compared with those with less than three children $(\mathrm{OR}=0.90$; $95 \% \mathrm{CI}=0.79$ to 1.02 ).

Current users of modern contraceptive methods had $26 \%$ significant reduction in terminated pregnancies compared with non-current users $(\mathrm{OR}=0.74$; $95 \% \mathrm{CI}=0.65$ to 0.84 ); the converse was true for unintended pregnancy. Women who had IPV were 1.49 $(\mathrm{OR}=1.49 ; 95 \% \mathrm{CI}=1.37$ to 1.62$)$ and $1.61 \quad(\mathrm{OR}=1.61$; $95 \% \mathrm{CI}=1.46$ to 1.77$)$ times as likely to have terminated and unintended pregnancies compared with women who had no IPV. Remarkably, women who had unintended pregnancy were 1.47 times as likely to have terminated pregnancy compared with those who had no unintended pregnancy (OR=1.47; $95 \% \mathrm{CI}=1.30$ to 1.65$)$. Women not currently married were 3.03 times as likely to have unintended pregnancy, but had $8 \%$ reduction in terminated pregnancy compared with those who are currently married or living with partner. Women with unmet need in contraceptive use were 7.51 as likely to have unintended pregnancies $(\mathrm{OR}=7.51 ; 95 \% \mathrm{CI}=6.78$ to 8.32$)$; however, they had $14 \%$ reduction in terminated pregnancy $(\mathrm{OR}=0.84$; $95 \% \mathrm{CI}=0.76$ to 0.92$)$. Overall, there were no differentials in the factors of terminated and unintended pregnancies between the NDHS 2003-2013 pooled data and NDHS 2013 data as presented in table 3.

\section{DISCUSSION}

Based on the findings of this study, overall, about one-tenth of Nigerian women had terminated and unintended pregnancies with slight decline in the past decade. The findings revealed that millions of Nigerian women in terms of absolute number have experienced unintended and terminated pregnancies in line with reports from previous studies. ${ }^{7}{ }^{17}$ Poor utilisation of modern contraception methods was remarkable because it is the basis of unintended pregnancy. This could be a prominent factor contributing to the level of unintended pregnancy and consequently induced abortion in Nigeria. The percentages of unintended and terminated pregnancies among women who currently use modern contraceptive methods were quite low. This is consistent to reports from several studies previously conducted to examine the level of contraception use. ${ }^{71619}$

Furthermore, older women, those not currently married, women with unmet need in contraceptive use and women currently employed had increase in terminated pregnancy, but reduction in unintended pregnancy. The geographical region and religious beliefs of respondents were significantly associated with terminated and unintended pregnancies. Educated women, those with high wealth index and women who experience IPV had increase in terminated and unintended pregnancies. These findings are consistent with many other studies on the correlates of terminated and unintended pregnancies. $^{7}$ 18-20 26-33 Though Nigerian government has recognised the problem of unintended and terminated pregnancies and dedicated to improving maternal healthcare services, evidence suggests that progress has 


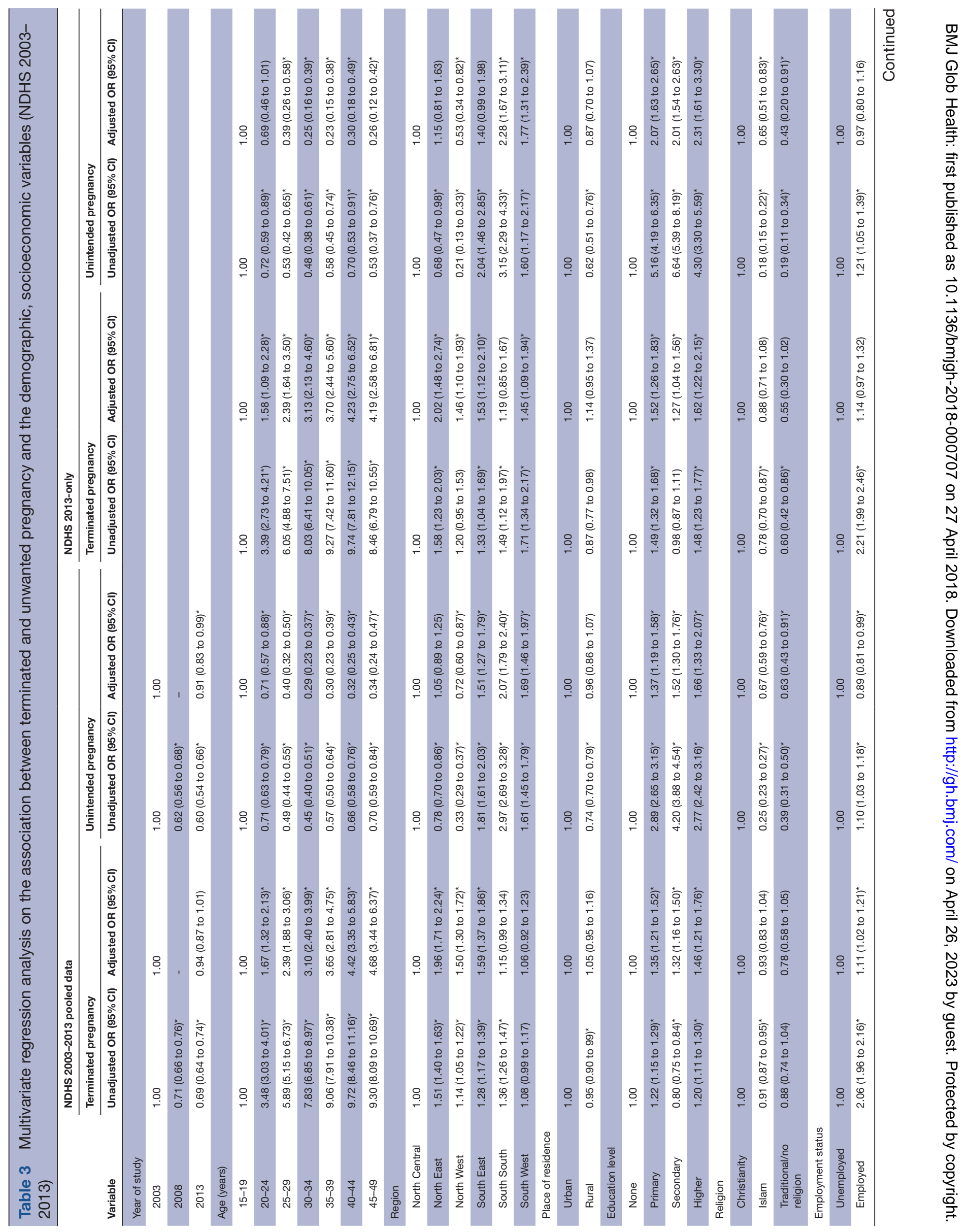




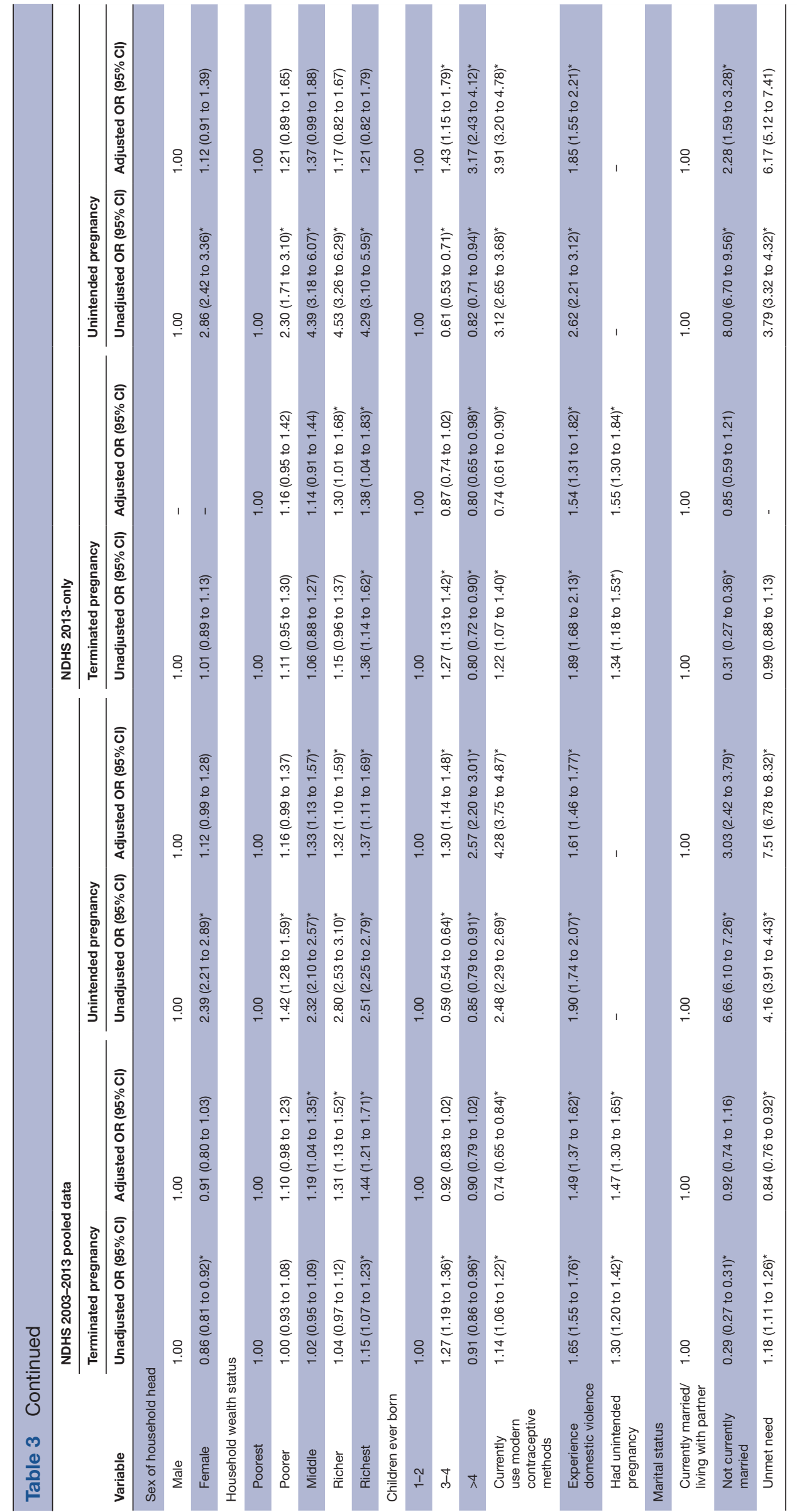


been inadequate, and complications from induced abortions remain a prominent factor of maternal morbidity and mortality. Findings from this study suggest that unintended pregnancy, a major contributory factor of most induced abortions exist in Nigeria.

Despite only a minimal number of women are eligible for legal abortion under existing law which is to save life, increased efforts are also needed to prevent unintended pregnancy in its entirety and to reduce levels of unsafe abortion and its negative health, social and economic effects. Though much effort have been made on how to advance the dialogue on unsafe abortion in Africa at large, which has been led by broad-based national partnerships and coalitions of women's groups, healthcare professionals, non-governmental organisations and public health activists, while regional bodies have also taken a stand on abortion, within the wider context of safe motherhood and reducing maternal mortality. ${ }^{34}$ It is paramount that policies and decision makers in Nigeria own up their duty to protect the lives of women who are vulnerable to the fatal consequences of unsafe abortion in cases of rape, sexual assault, incest and where continuing the pregnancy would endanger the physical or mental health of the woman or the woman's life. As millions of Nigerian girls still attend schools, thereby increasing the marriage age, the inadequate provision of family planning and abortion care will mean that Nigeria risks losing a growing number of its young women through unsafe sexual activity, unintended pregnancy, unsafe abortion and early childbearing.

\section{Strengths and limitations}

This study was based on nationally representative secondary data and the findings are generalisable for the women aged between 15 and 49 years. Sample size was considerably large that were collected from three rounds of surveys which allowed reporting the trend in the prevalence of terminated and unintended pregnancy. Nevertheless, a major drawback is that cross-sectional study design as employed is not sufficient to critically examine causality. Also, the outcome variables were measured based on self-reported data which can be subject to misclassification bias. The study intended to estimate induced abortion; nonetheless, respondents might have as well reported spontaneous abortion thereby leading to overestimation of terminated pregnancies. In addition, since the study captured the life time experience of women on terminated and unintended pregnancies, the occurrence of recall bias is very likely as highly multigravida women could have lost track of certain sexual and reproductive events that preceded some pregnancies, thereby leading to under-reporting of unintended pregnancies.

\section{CONCLUSION}

Based on analysis of NDHS data, this study found that the issue of terminated and unintended pregnancies still exist among Nigerian women. In addition, majority of the women reported not using any modern contraceptive methods and had significantly higher odds of abortion and unintended pregnancy. The underlying causes behind the prevalence rates of both terminated and unintended pregnancy remains a subject for further investigation. Regional and socioeconomic disparities need to be addressed through proper policy action in order to promote reproductive health and well-being in the population. Most importantly, improvement in maternal healthcare services is needed to aid women during the challenges of unintended pregnancy.

Correction notice This article has been corrected since it first published. The licence type has changed from CC BY to CC BY NC.

\section{Acknowledgements The authors thank the MEASURE DHS project for their support and for free access to the original data.}

Contributors SY and ME contributed to the study design, the review of literature and analysis of literature, manuscript conceptualisation and preparation. AA, OAU, $\mathrm{ME}, \mathrm{OU}, \mathrm{AH}$ and VS critically reviewed the manuscript for its intellectual content. SY had final responsibility to submit for publication. All authors read and approved the final manuscript.

Funding The authors have not declared a specific grant for this research from any funding agency in the public, commercial or not-for-profit sectors.

\section{Competing interests None declared.}

Patient consent Not required.

Ethics approval The Nigerian DHS is conducted according to the local Nigerian research ethics requirements. Data for this analysis were accessed via the publicly available DHS data sets, with access granted through the DHS programme. As this was a secondary data analysis, further research ethics approval was not required; however, in accordance with DHS regulations, all data extracted from the NDHS for the purpose of this study were handled as confidential and survey respondents remained unidentified. This study conforms to the principles of the Declaration of Helsinki.

Provenance and peer review Not commissioned; externally peer reviewed.

Data sharing statement No additional data are available.

Open Access This is an Open Access article distributed in accordance with the Creative Commons Attribution Non Commercial (CC BY-NC 4.0) license, which permits others to distribute, remix, adapt, build upon this work non-commercially, and license their derivative works on different terms, provided the original work is properly cited and the use is non-commercial. See: http://creativecommons.org/ licenses/by-nc/4.0/

(C) Article author(s) (or their employer(s) unless otherwise stated in the text of the article) 2018. All rights reserved. No commercial use is permitted unless otherwise expressly granted.

\section{REFERENCES}

1. Santelli J, Rochat R, Hatfield-Timajchy K, et al. The measurement and meaning of unintended pregnancy. Perspect Sex Reprod Health 2003;35:94-101.

2. Ganatra B, Gerdts C, Rossier C, et al. Global, regional, and subregional classification of abortions by safety, 2010-14: estimates from a Bayesian hierarchical model. The Lancet 2017;390:2372-81.

3. WHO,Safe Abortion. Technical and Policy Guidance for Health Systems. 2nd edition. Geneva: Switzerland: World Health Organization, 2012.

4. Peterson HB, Darmstadt GL, Bongaarts J. Meeting the unmet need for family planning: now is the time. Lancet 2013;381:1696-9.

5. Bankole A, Adewole IF, Hussain R, et al. The incidence of abortion in Nigeria. Int Perspect Sex Reprod Health 2015;41:170.

6. Faye CM, Speizer IS, Fotso JC, et al. Unintended pregnancy: magnitude and correlates in six urban sites in Senegal. Reprod Health 2013;10:2-10. 
7. Sedgh G, Bankole A, Oye-Adeniran B, et al. Unwanted pregnancy and associated factors among Nigerian women. Int Fam Plan Perspect 2006;32:175-84.

8. Abir T, Agho KE, Page AN, et al. Risk factors for under-5 mortality: evidence from Bangladesh Demographic and Health Survey, 20042011. BMJ Open 2015;5:e006722.

9. Asuquo E, Orazulike N, Onyekwere E, et al. Unintended Pregnancy among Married Antenatal Clinic Attendees in a Tertiary Institution in Nigeria. Br J Med Med Res 2017;19:1-11.

10. Fisher B, Naidoo R. The geography of gender inequality. PLoS One 2016;11:e0145778.

11. Corroon M, Speizer IS, Fotso JC, et al. The role of gender empowerment on reproductive health outcomes in urban Nigeria. Matern Child Health J 2014;18:307-15.

12. Federal Ministry of Health (Nigeria). National Human Resources for Health Policy. 2017.

13. Oye-Adeniran BA, Long CM, Adewole IF. Advocacy for reform of the abortion law in Nigeria. Reprod Health Matters 2004;12:209-17.

14. Emechebe C, Njoku C, Udofia U, et al. Complications of induced abortion: Contribution to maternal mortality in a tertiary center of a low resource setting. Saudi J Health Sci 2016;5:34-8.

15. World Health Organization (WHO). Unsafe abortion: global and regional estimates of the incidence of unsafe abortion and associated mortality in 2008. Geneva: WHO, 2011.

16. Abiodun OM, Balogun OR. Sexual activity and contraceptive use among young female students of tertiary educational institutions in Ilorin, Nigeria. Contraception 2009;79:146-9.

17. Oriji VK, Jeremiah I, Kasso T. Induced abortion amongst undergradute students of University of Port Harcourt. Niger J Med 2009:18:199-202.

18. Olukoya AA. Pregnancy termination: results of a community-based study in Lagos, Nigeria. Int J Gynaecol Obstet 1987;25:41-6.

19. Habte D, Teklu S, Melese T, et al. Correlates of unintended pregnancy in Ethiopia: results from a national survey. PLoS One 2013;8:e82987.

20. Pallitto CC, García-Moreno C, Jansen HA, et al. Intimate partner violence, abortion, and unintended pregnancy: results from the WHO Multi-country Study on Women's Health and Domestic Violence. Int J Gynaecol Obstet 2013;120:3-9.
21. Silverman JG, Decker MR, McCauley HL, et al. Male perpetration of intimate partner violence and involvement in abortions and abortionrelated conflict. Am J Public Health 2010;100:1415-7.

22. Miller $\mathrm{E}$, Jordan $\mathrm{B}$, Levenson $\mathrm{R}$, et al. Reproductive coercion: connecting the dots between partner violence and unintended pregnancy. Contraception 2010;81:457-9.

23. Nigeria Demographic and Health Survey 2003. Abuja, Nigeria: ICF International and Rockville, MD, USA, 2003.

24. Nigeria Demographic and Health Survey 2013. Abuja, Nigeria: ICF International and Rockville, MD, USA, 2013.

25. Royston P. Ptrend: Stata module for trend analysis for proportions. Boston College Department of Economics. 2014 https://ideas.repec. org/c/boc/bocode/s426101.html (cited 9 Apr 2018).

26. Oye-Adeniran BA, Adewole IF, Umoh AV, et al. Characteristics of abortion care seekers in south-western Nigeria. Afr J Reprod Health 2004;8:81-91.

27. Sudhinaraset M. Reducing unsafe abortion in Nigeria. Issues Brief 2008;3:1-3

28. Antai D, Adaji S. Community-level influences on women's experience of intimate partner violence and terminated pregnancy in Nigeria: a multilevel analysis. BMC Pregnancy Childbirth 2012;12:2-15.

29. Gite A, Liulseged N, Seyife H, et al. Unintended Pregnancy: Magnitude and Associated Factors among Pregnant Women in Arba Minch Town, Gamo Gofa Zone, Ethiopia. Reprod Syst Sex Disord 2016;5:193.

30. Klima CS. Unintended pregnancy. Consequences and solutions for a worldwide problem. J Nurse Midwifery 1998;43:483-91.

31. Finer LB, Zolna MR. Unintended pregnancy in the United States: incidence and disparities, 2006. Contraception 2011;84:478-85.

32. Al Riyami A, Afifi M, Mabry RM. Women's autonomy, education and employment in Oman and their influence on contraceptive use. Reprod Health Matters 2004;12:144-54.

33. Shapiro D, Tambashe BO. The impact of women's Employment and education on contraceptive use and abortion in Kinshasa, Zaire. Stud Fam Plann 1994;25:96-110.

34. Article 34, Protocol to the African Charter on Human and People's Rights on the Rights of Women in Africa, as adopted by the Conference of Heads of States and Governments. Maputo,Mozambique, 2003. 


\section{Correction: Prevalence and determinants of terminated and unintended pregnancies among married women: analysis of pooled cross-sectional surveys in Nigeria}

Yaya S, Amouzou A, Uthman OA, et al. Prevalence and determinants of terminated and unintended pregnancies among married women: analysis of pooled cross-sectional surveys in Nigeria. BMJ Global Health 2018;3:e000707.

This article has been corrected since it first published. The licence type has changed from CC BY to CC BY NC.

Open Access This is an Open Access article distributed in accordance with the Creative Commons Attribution Non Commercial (CC BY-NC 4.0) license, which permits others to distribute, remix, adapt, build upon this work non-commercially, and license their derivative works on different terms, provided the original work is properly cited and the use is non-commercial. See: http://creativecommons.org/icenses/by-nc/4.0/

(C) Article author(s) (or their employer(s) unless otherwise stated in the text of the article) 2018. All rights reserved. No commercial use is permitted unless otherwise expressly granted.

BMJ Glob Health 2018;3:e000707corr1. doi:10.1136/bmjgh-2018-000707corr1

(A) Check for updates 